\title{
Research on Construction of Public Cultural Service Systems of New Socialist Countryside Construction
}

\author{
Jing Zhao ${ }^{1, a}$ \\ ${ }^{1}$ Anyang Vocational and Technical College; Anyang Henan; 455000 \\ ${ }^{a}$ email
}

Keywords: new rural public cultural service system; minimum cultural life of farmers; new countryside construction

\begin{abstract}
The current service system new problems in rural public cultural of Henan province, such as lack of knowledge, institutional flow, lack of investment, lack of funds, lack of supply, aging facilities, market lag, dregs and other issues. Construction of Henan rural public cultural service system, which effectively protect the farmers the minimum cultural life, it is a complicated systematic project, we need to do the following aspects: the transformation of government functions, establishing cultural management system in rural areas; to further strengthen the rural public culture infrastructure; rural public cultural products production, innovation and social support mechanisms; construction of rural cultural market system, the development of rural cultural characteristics; security funds into the construction of public cultural service system.
\end{abstract}

\section{Introduction}

Fifth Plenary Session of the Seventeenth Party Congress pointed out that to increase government funding for non-profit cultural undertakings, and gradually form a more complete coverage of the whole society public cultural service system. Sixth Plenary Session "decision on building a harmonious socialist society a number of major issues," stressed that we should continue to develop nonprofit cultural programs as the main approach to ensuring people's cultural rights and interests, accelerate the establishment of benefit all public cultural service system. Accelerate the development of public cultural services, utilities, construction of public cultural service system, is an important part of one of the objectives and tasks of the national cultural development plans five-second period. And further strengthen the construction of rural public culture, building rural public cultural service system, and it is the cultural construction of a new socialist countryside important content and objectives ${ }^{[1]}$.

Hubei province rural public cultural service system, refers to the process of building a new socialist countryside in Henan province as a regional unit, it aims to develop rural public cultural undertakings, improve farmers' ideological and cultural level, to enhance the degree of civilization in rural areas, cultivating rural cultural and ecological environment, safeguard the people's basic cultural rights and interests of farmers and to meet the basic cultural needs of the public cultural service system.

\section{Current Issue of Henan Rural Public Cultural Service}

Lack of knowledge, system is not smooth. CPC Central Committee and the State Council, issued a series of policy documents for rural cultural work, in recent years, Henan Province has formulated the "Henan cultural undertakings and cultural industry development plan (in 2006 - 2012 years)," Twelfth Five-Year Social Henan Province new countryside construction planning implementation Outline. These documents for the construction of a new socialist countryside in Henan cultural service system problem, have important guiding significance, wherein the step of overall planning and design, it is better for us to portray a blueprint for a new socialist countryside public cultural work. However, according to our research and found that the rural grassroots party and government leaders are still widespread emphasis on economic growth and ignore the negative tendencies 
farmer culture quality of life, culture is generally considered a soft target, dispensable. The main problem of rural grassroots culture in the presence of the management system is manifested in the following two aspects: First, the prevalence of rural grassroots cultural professionals do not dedicated full-time problems, as they are firefighters, one size fits all. Second, the rural cultural services bull management, coordination ring true, often resulting in the rural culture of the force weakening the impact of the integration of cultural resources in rural areas. Technology seminars for farmers, and legal advocacy, read books and newspapers, information exchange, cultural counseling, sports and other activities undertaken difficulty concentrating, nonprofit cultural functions of varying degrees weakened.

The investment and funds is not enough. For the field investigation, both the farmer and cadres are the main difficulties of the current rural cultural work first due to government financial investment, lack of funds, resulting in a lack of activities, culture and other issues of lack of talent. In fact, the lack of cultural facilities and cultural talents remain difficult issues to a considerable extent a reflection and also reflects the Government's financial investment in the cultural insufficient. Due to lack of financial resources and adequate incentives, in some parts of rural cultural service / network break, line break, were scattered. Part of grass-roots could emphasis on economic development, one-sided pursuit of economic GDP, ignoring culture. Grassroots Party committees, government leadership believes rural cultural service system is a matter of the superior administrative culture department, so the culture does not really work agenda. It was widely felt cultural work hard to make significant accomplishments and benefits, grab samples do not grab a good grasp of a bad grab sample, thereby resulting in long-term culture of work / status weak, easily overlooked. Because of the cultural center township finance minimal investment, poor management results in a considerable part of the cultural center useless ${ }^{[2]}$.

Supply shortage, aging facilities. From a practical point of view of cultural facilities, cultural facilities locally owned farmers' subjective perception and status of the Government to provide farmers in the type and scope of the basic agreement. On the use of cultural facilities, from the farmer's point of view, the most frequently followed by cultural activity room, basketball court, cable television, temples; township cadres that farmers use most frequently followed by cable television, temple churches, cultural activity room and a cinema. Rural grassroots cultural investment on the one hand a serious shortage of the total, on the one hand and appeared limited investment efficiency is not high, idleness, waste larger phenomenon. The original system, the idea has become increasingly unsuited to the requirements of a new historical stage of cultural development, reform is urgently needed, is imperative.

Due to the slow growth of farmers' income, rural cultural market development lags behind. In some of the villages, farmers' per capita expenditure is only engaged in cultural and educational undertakings of a few dollars, while per capita spending cash for gambling superstitions like already exceeds the per capita expenditure on culture. This shows that the farmers' income is too low, monotonous life and rural cultural market development is seriously lagging behind the root cause. Slow growth of farmers' income and the impact of the fiscal revenue, restricted investment in rural cultural construction, these aspects are resulting in a difficult position of rural culture fully play its role. Improve the cultural quality of farmers, rural active cultural life, safeguard consumer interests peasant culture, respect for farmers' rights and interests of the cultural life is still a long way to go.

\section{Construction of Henan Rural Public Cultural Service System}

The transformation of government functions, we should establish cultural management system in rural areas. First, the cultural administration departments should strengthen mechanisms for reform and innovation. First, speed up the reform of nonprofit cultural institutions. The province's counties and municipal cultural centers, libraries reform is to increase investment, conversion mechanism, enhance the vitality, and improve public services at last. Deepen the internal reform of labor, personnel, distribution and other aspects, establish and improve competition, incentive and restraint mechanisms, and assuming responsibility, full implementation of the appointment system and the labor contract system. County cultural centers, libraries and cultural centers, etc. belonging to the 
township public institutions can't be disguised or entrepreneurial enterprise, change the use of its cultural facilities in any form auction, lease. County, township cultural institutions to the needs of rural, grassroots-oriented, to develop an annual rural public cultural project implementation plan, a clear service standards, improve service, to carry out the flow of cultural services, to strengthen the backbone of culture and cultural center of rural households free training and coaching, support reward private culture.

Secondly, the content of the notification format and file transfer mode is not standardized, the lack of the necessary official, serious, resulting in teachers and students do not care, do not pay attention, cause information loss in the transmission process, aliasing, alienation or even anti-oriented, seriously affecting work effectiveness. Mainly in the part of the information transfer body is not strong sense of responsibility, leading to lack of authoritative information, and even the loss of authority; frequent change of information as in the case did not check the authenticity of the information, or even contradictory information content around. In addition, the lack of information in the process of passing the necessary sense of responsibility and the necessary continuity, the same information is only as a baton pass out from their hands, after passing the integrity of the information is no longer involved, whether timeliness and timely information has been passed to reach receiving body ${ }^{[3]}$.

Thirdly, strengthen macro-control. Cultural market management mechanism should cultural products operators purchase channels, purchase link in strict checks to stop those morbid, lower cultural products into the market, and guide people to engage in healthy, elegant cultural consumption. For the development of the province's rural cultural market imbalance, cultural departments at all levels should focus on supporting the establishment and development of rural cultural market, for local conditions to develop specific strategies and planning and construction of rural cultural market management. Give full play to the leading role of historical and cultural city, from near and far, to promote the vigorous development of the rural cultural market.

Finally, establish and improve various management systems. County and township cultural management agencies must be based on relevant laws and regulations, local conditions to establish and improve various management systems in the region, including specific operational methods and implementation details. Enhance the legal concept of cultural operators, the standardized management of cultural market. According to the characteristics of rural cultural market, cleaning up dead and empty, strengthen the focus on the issue, focusing on time, supervision and inspection of key areas. We can straighten concentrated assault and daily self-management combined, improve the management system, and establish a dominant position of authority-oriented cultural sector in the cultural sector, collaboration with the public security, industry and commerce co-management departments to effectively combat all kinds of illegal business activities. Establishment of grass-roots trade associations can promote industry self-regulation, relying on the masses, mobilize the masses and strengthen supervision, all-round, multi-level management for rural cultural market.

\section{Development and Management of Rural Culture}

On the one hand, adhere to grasping prosperity, intensifying management, in order to achieve prosperity and promote the management, to manage and promote the prosperity of the win-win situation. We should vigorously strengthen rural cultural market management, and create a healthy, positive cultural production and consumption environment. In order to strengthen and enrich the county cultural market administrative law enforcement team, we give full play to the supervisory role of township cultural stations, improve the rural cultural market management system, to strengthen the law enforcement forces, strengthen supervision and improve the level of law enforcement. Rectify and standardize the market order, crack down on various illegal activities, resolutely ban unlicensed. Focus on strengthening the entertainment, film screenings, publications printing and sales, Internet cafes and other aspects of management, determined to fight against the spread of pornographic, feudal superstitions and other illegal activities to ensure the healthy and orderly development of rural cultural market. On the other hand, we must strengthen the management team of its development and improve comprehensive law enforcement capacity and 
enhance the quality of law enforcement. Strengthen management at different levels, the establishment of county, township and village levels, urban-rural integration management network. Especially establish the township market management team level to full-time and part-time combination, build three-dimensional network of law enforcement county, township and village comprehensive one. Strengthen cultural market management team of its own building, regularly carry out theoretical study and business knowledge training, competitions are held regularly enforcement practices and operational guidance report, good mentoring, improve the basic quality of rural cultural market management, the level of policy and enforcement capabilities. Full-time and part-time managers should meet regularly to business meeting, timely information, and summarize the work of the deployment, thus contributing to the implementation of the cultural market management activities ${ }^{[4]}$.

Further strengthen rural public cultural infrastructure. Adhere to government-led, relying on the township to the village as the key to the farmers for the object, the development of the county, township and village cultural facilities and cultural activities, building hardware network of rural public cultural services. Realize county cultural centers, libraries, the township has comprehensive cultural stations, village cultural activity room. County museum have comprehensive functions, it can strengthen the digital library construction. To combine the township institutional reform and stations (the) integration, the formation of sets of books to read, radio and television, education, theatrical performances, science and technology, science training, promotion of sports and youth activities is one of the comprehensive cultural center, and to be equipped with full-time staff to manage. Village cultural activity rooms are clearly responsible for specific multi-use by village cadres, In order to give full play to the important role of rural primary and middle schools in rural areas in terms of cultural activities to promote primary and secondary schools library, electronic reading timing of farmers nearby open to primary and secondary schools built to promote its advanced culture, science and sports training exercise stronghold. For edges and poor areas, we can conduct mobile services to the rural cultural flow with multi-functional cultural vehicles from the government, in order to carry out flexible, diverse, convenient and cultural services. Henan arranged 20 million Yuan of special funds each year, support of transformation, the new township cultural stations 100 , accelerate cultural information resources sharing project that is primary point of service in rural areas. In order to implement Henan Farmer Fitness Project, Henan Province, the new year of 1000 rural sports complex. Local financial support for the construction of township farmers sports base, in order to promote the farmers to carry out various forms of sports.

Rural public cultural products is important, as well as innovation and social support mechanisms. For important public cultural resources to make reasonable adjustments, gradually increase the amount of resources for rural services. "Henan Daily" rural version, the Henan People's Radio and TV stations run by rural Henan frequency, channel, cities (to) party newspapers and city (prefecture) and county radio and television stations have run for the rural grass-roots Edition, frequency and channel three rural services, public cultural services to provide useful products for the province's farmers. Encourage the development of small and medium bookshops, specialty bookstores, community bookstores and online bookstore. Focus on the development of rural forms of publication distribution outlets, outlets and rental points to encourage all kinds of capital investment in rural distribution of publications, expand the rural market publications. To increase the focus on rural theme topic funding efforts, the rural theme included artistic production stage, film, radio and television production, publishing all kinds of books and audio-visual products plan to ensure rural theme of literary works produced in the total amount of the account for a certain proportion. Important cultural projects and cultural products get government subsidies, government procurement, rural public cultural products directly sent to the countryside. Purchase outstanding screenplay for rural copyright free to use grass-roots arts groups, adapted into the province's farmers loved cultural programs.

County (city) branch library gradually implement the system, a rich collection of books, to form a unified procurement, unified cataloging books distribution system, give full play to the role of radiation County Library township, village library, and promote the county, township and share 
books and documents. Henan Province in accordance with government funding, and encouraging social contributions, farmers self-management, operation of the market requires the development of the cultural center family as the basis to support the farmers run farm house. Innovation and social support mechanisms, the province's agriculture-related agencies and departments should vigorously support rural public cultural service system, establish and improve long-term mechanism to support. At the same time, but also a wide range of social forces organized and smooth support channels. Equipment donated by aid and cultural products, sharing cultural resources, business cooperation, personnel training, work instructions, etc., help organize a counterpart support activities, and effectively help solve rural problems relative lack of cultural products. Guide and encourage contributions and social forces to set up libraries, museums, cultural centers, etc., to be preferential policies in land and taxation. Social power through legal authority to rural public cultural undertakings donations, charitable donations will be included in the scope. Mobilize urban units and rural residents in various ways to donate televisions, computers, radios, books, magazines, audio-visual products, encourage cultural rights of rural cultural institutions permission to use their works free of charge. The province's rural institutions, enterprises, schools and cultural facilities to be open to local farmers as much as possible, and actively carry out cultural services.

Henan uses market access, price regulation, tax incentives and other policies to actively guide the various market players released in publishing, film screenings, theatrical performances, network services and other areas, develop rural cultural market. Henan peasants to support self-financing their own organizations, self-financing, self-managed way to set up farmer publishing house, film projection teams, etc., support the development of folk troupes and folk opera. Encourage the development of paper cutting, painting, ceramics, clay sculpture, carving, weaving, jade ornaments, imitation artifacts and other folk crafts projects with national traditions and characteristics of Hubei, to support the development of rural folk arts and crafts industry. In the system construction of Henan rural cultural market, should the county, township cultural centers, stands as the vanguard of the rural cultural market, cultural specialist as rural culture marketplace.

Henan current rural cultural market is showing a multi-channel state, collective, individual three joint investments and management, the new pattern of pluralism and multi-level development. Rural areas of Henan appeared a large number of cultural specialist, brings fresh atmosphere, comply with the requirements of the rural cultural market economy. Awareness of their participation in the cultural market economy is strong, with a flexible market mechanism and self-hematopoietic function, showing strong vitality. Develop rural private culture. Through public office to help, policy support to encourage farmers running the culture, cultivate microscopic body to carry out various rural-oriented, cultural and business activities for farmers, so that farmers are the masters in public cultural building a new countryside, becoming the cultural construction in rural areas in Henan the true subject. Take effective measures to stabilize and develop full-time, part-time combination of rural cultural team, and gradually improve the overall quality of the rural cultural market practitioners. Qualification system for the implementation of rural cultural institutions personnel in accordance with relevant laws and regulations, to encourage college graduates to rural Hubei engaged in cultural work. Through awards, government subsidies, etc., to fully mobilize the professional art personnel and the rural non-professional artistic talents of enthusiasm for work, strengthen rural cultural team of education and training. To actively training farmers in Henan cultural backbone, give full play to folk artists, cultural hotshots in the mass base of life, the role of folk culture heritage and development aspects of rural culture active consolidate cultural construction in rural areas.

\section{Guarantee Funding of Rural Characteristics and Culture}

According to the financial support for agriculture is higher than the three requirements, Henan Province adhere to the stock of a moderate change, the focus of the principle of incremental tilt, ensure that the new fiscal spending and investment in fixed assets to invest more in new rural construction, Henan Province has adjusted national income distribution structure, expand public finance coverage in rural areas. In the use of agriculture-related funds management, capital of 
Henan Province to adhere to the same nature, the same sources, the same principles of supervision and management, county-based, planning guidance, project-driven, focused investment funds for agriculture-related integration improve capital efficiency and effectiveness. Various types of funds to implement projects directly, strict supervision, to ensure that earmarked. To gradually increase the proportion of investment in government finance for the construction of rural public culture, long-term mechanism of financial funds stable growth ${ }^{[5]}$.

Policy financial institutions to increase support for rural public cultural service system in Henan agency efforts to long-term loans. To guide commercial banks to increase rural public cultural services, cultural production and circulation areas such as financial services efforts. Continue to promote the reform of rural credit cooperatives, micro-credit loans and actively promote farmers and farmers guaranteed loans, and explore effective ways to grant large loans. To take financial assistance, subsidized credit, equity management, financing, guarantees, etc., encourage and guide social capital to invest in all aspects of the construction of Hubei rural public cultural service system.

Governments at all levels in Henan Province to co-ordinate planning, increase of cultural service system of public investment in rural areas, to expand the scope of public finance coverage in rural areas, towns and villages used to continuously improve the ratio. Ensure that the central transfer payments for a certain number of township and village cultural construction. And around the City, Henan Province to set up special funds for the construction of rural culture, in order to ensure that key cultural construction of rural financial needs, improve efficiency in the use of fiscal funds. "Township cultural stations cultural facility maintenance of special funds Interim Measures," the provisions of Henan Province during the second five: all included in the township cultural stations maintenance of facilities and equipment acquisition projects, subsidy standards for each project 20 million.

Construction of township cultural stations, a predetermined station house area not less than 500 square meters, specifically configured to three bedroom, namely books and a reading room (books, newspapers, electronic reading room), not less than 100 square meters; a cultural and technological training room (cultural knowledge, science and technology, and other grassroots cultural backbone training places), not less than 100 square meters; an office (office, storage, duty rooms, etc.) is not be less than 50 square meters; a multi-function hall (including various cultural rehearsals, small performances, painting exhibitions, song and dance entertainment, etc.) shall not be less than 250 square meters. Funds are also used to buy electronic reading device, the basic instrument of books, newspapers and cultural activities, audio-visual equipment, tables and chairs. In addition, we can also take way to provide a healthy and progressive farmers loved cultural products and services, such as government procurement, farmers enjoy, government pay or farmers choice, so achieve the basic cultural rights and interests of the peasant masses, and meet the broad masses of peasants seeking rich, knowledge, seeking music comprehensive cultural needs.

\section{Conclusions}

Construction of Henan rural public cultural service system, we already have a good working basis. In the new socialist countryside construction in Henan, we want to change cultural management functions of the government, the establishment of cultural management system in rural areas, the rural culture of innovation management mechanism, further strengthen the rural public cultural infrastructure, implementation of good six key projects, improve the rural cultural market system, and effectively protect the investment in the building should be targeted to build realistic, scientific and strategic evaluation system services improve rural culture, rural public cultural service system, to seize the opportunity and momentum, together, hard work, the new rural Henan Province public cultural service system will be able to build successfully completed during the second five, so as to provide effective public services for the Chu culture children, effectively protect the farmers the minimum cultural life. 


\section{Acknowledgment}

This is the initial result of Science and Technology Department of Henan Province, 2014 soft science and technology project.

Project Fund Number: 142400410222.

\section{References}

[1] Henan cultural undertakings and cultural industry development plan (2006 - 2012) [N] Henan Daily, 2013-06-03.

[2] Henan second five socialist new rural construction planning Implementation Outline [N]. Henan Daily , 2013-08-17.

[3] Investigation of County Culture [J]. Jiang han Forum, 2004 (11).

[4] Liu baochang, Situation in Rural Henan cultural life survey and analysis [M] // 2006 Henan Blue Book: cultural restructuring Zhengzhou: Henan People's Publishing House, 2006.

[5] Liu baochang, Chen jingzhou, Henan cultural market system [J]. Hubei University of Economics, 2007 (2). 